\title{
Evaluation of Environmental Noise in Urban areas: A Noise Pollution Assessment Approach
}

\author{
Misha Roy $^{1,2 *}$, Farzana Shamim ${ }^{1}$, Rahul Majumder ${ }^{1}$, Chaitali Ghosh ${ }^{1}$ and Saibal Chatterjee ${ }^{1}$ \\ ${ }^{1}$ Centre for Environmental Studies, Vidyasagar University, Midnapur, West Bengal, India \\ ${ }^{2}$ Directorate of Distance Education, Vidyasagar University, India \\ *Corresponding Author: Misha Roy, Directorate of Distance Education, Centre for Environmental Studies, Vidyasagar University, \\ Midnapur, West Bengal, India.
}

Received: January 10, 2022; Published: January 31, 2022

\begin{abstract}
Noise Pollution has become a serious health issue nowadays and emerging as a serious pollutant. This study is carried out in three semiurban towns to evaluate the impact of noise pollution in these areas. A total of 69 locations are selected in Asansol, Bankura, and Midnapore town including the Silent, Residential, Commercial, and Industrial zone. Since the noise level varies with atmospheric conditions, hence the study is divided into premonsoon, monsoon, and post-monsoon seasons. L1, L5, L10, L50, L90, L95, L99, Equivalent sound pressure level (Leq), Noise climate (NC), Noise pollution level (Lnp), and Noise traffic Index (TNI) were computed for evaluating the intensity of noise pollution. The result reveals that the equivalent sound pressure level (Leq) is much higher than the standards in all locations of the silent zones. Noise pollution level (Lnp) and Noise traffic Index (TNI) are also computed high in commercial and heavy traffic zones. The Noise climate (NC) value shows not much variation in noise intensity with pre-post and monsoon climates. This is a pioneer study on noise quality evaluation in these locations. This study will further help in preparing future management plans to combat noise pollution in these areas.
\end{abstract}

Keywords: Noise pollution; Equivalent noise level (Leq); Traffic noise; L99;L90;Noise climate (NC); Noise traffic Index (TNI); Noise pollution level (Lnp)

\section{Abbreviations \\ Leq : Equivalent noise level. \\ NC : Noise climate. \\ TNI : Noise traffic Index. \\ Lnp : Noise pollution level.}

\section{Introduction}

Noise - the unwanted sound- is an obtrusive form of environmental pollution. It is derived from the Latin word "nausea" implying 'unwanted sound' or 'sound that is loud, unpleasant or unexpected'. According to health specialists, noise pollutions accounts for around $24 \%$ of the pollutant loads responsible for health risks [1]. Noise pollution impacts the activity of human or animal life, most of them are harmful to some extent. The sources of outdoor noise worldwide are mainly machines, transportation, and propagation system [2]. This high noise intensity causes stress, annoyance, sleeping disturbances, hormonal changes, increase in blood pressure, various cardiovascular diseases and coronary artery diseases, the endocrine effect from noise, cognitive disablement (in children), etc [3 - 5]. The effect of noise has been studied on humans, animals, and plants [6-8]. Changes in blood pressure, heart rate, changing the level of the stress hormone, and increase in cardiovascular risk are also seen as non-auditory health effects $[9,10]$. 
Since the seventies, the noise has been considered a major problem of annoyance in many major cities across the globe [11]. Road traffic noise is the big challenge for urban planners and environmental engineers to overcome in cities [12]. Banepa, a semi-urban town of Nepal showed how continuous exposure to a high level of noise can cause serious stress on the auditory and non-auditory, and nervous systems of the city dwellers $[13,14]$. It is also the leading cause of annoyance for the exposed population mainly triggered due to the poor conditions of the engine [15]. There are various studies conducted on traffic noise pollution, and the results reveal severe health problems such as physical and psychological irritation, poor human performance and actions, hypertension, heart problems, tiredness [16]. Studies conducted by the National Environmental Engineering Research Institute (NEERI) revealed that the noise levels in all the zones of Delhi far exceeded the prescribed standards. Similar results was also found from Mumbai, Kolkata, Jauipur and Pudukkottai, Taminadu [17-20]. A study in Agartala, Tripura through fuzzy modeling shows that how workers of government offices, private organizations, and commercial business centers are exposed to heavy traffic noise pollution and the disturbances on their work efficiency and increased annoyance [21]. Nowadays, local authorities and environmentalists are recognizing the importance of monitoring trends in noise pollution while developing mitigating plans. However still now the causes and effects of noise pollution have not attracted much attention yet unlike other pollutants [22]. The noise pollution management is devoid of sufficient knowledge about its harmful effects and dose-response relationships. This study reports for the first time the community noise level measured in fast-developing semi-urban areas of Bankura, Asansol, and Midnapore town, West Bengal, India. The present work analyses the noise pollution during the morning peak hours and evening rush hours. A large number of set of data were recorded in a random manner in order to account for statistical temporal variation in traffic flow condition.

\section{Materials and Methods}

\section{Study Area}

The present study is conducted in urban towns of Asansol $\left(23.68^{\circ} \mathrm{N}, 86.99^{\circ} \mathrm{E}\right.$; Elevation: $111 \mathrm{~m}$; Bankura $\left(23.25^{\circ} \mathrm{N}\right.$; $87.07^{\circ} \mathrm{E}$; Elevation: $78 \mathrm{~m}$, and Midnapore $\left(22.25^{\circ} \mathrm{N}, 87.65^{\circ} \mathrm{E}\right.$; Elevation: $\left.23 \mathrm{~m}\right)$ situated in West Bengal India. Sixty-nine locations were selected in silent zones which include Hospitals, Schools and Universities, Residential zone, Heavy traffic zone, and Industrial zone.

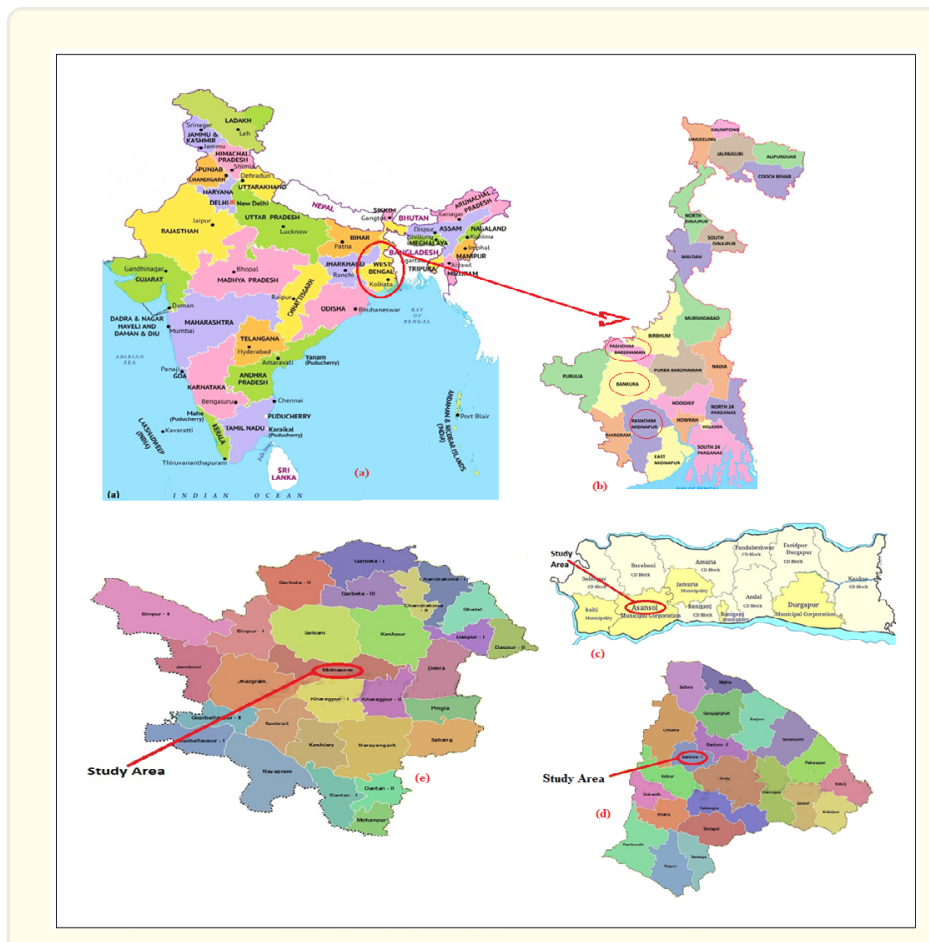

Figure 1: Study Area Map (c) Asansol, (d) Bankura, (e) Midnapore. 


\section{Asansol}

Asansol is an urban-industrial town, the town is a fast-growing and rapidly urbanizing industrial zone and the second largest and most populated city of West Bengal. The area has an urban population of 1,243,414 populations (2011, Census). The climate of Asansol is of "Aw" (Tropical Savanna Climate), according to the Köppen Climate classification. The town has grown in all sectors, and in recent times has become an important center for business and commercial activities. The increase in settlements, business, and commercial hubs have increased the traffic load of the town. The infrastructure growth has resulted in severe noise pollution all around the town.

\section{Bankura}

Bankura is a city in the state of West Bengal, India. It is a part of the Bardhaman division of the State. Bankura district is bounded by Bardhaman district in the northwest and PaschimMedinapure district in the south. The western portions are characterized by undulating terrain with many hills and ridges. Bankura has a tropical monsoon climate (Koppen, Am). It is predominantly a rural area with $89 \%$ of the population living in rural areas and only $11 \%$ living in the urban area. According to the 2011 census, Bankura city had a population of $137,386.21 .5 \%$ of the total geographical area of the city is forestland. With the presence of the Damodar river, in the northern part, flourished the growth of several coal mines.

\section{Midnapore}

Midnapore or Medinipur is a city in the West Bengal state of India. It is situated on the banks of the Kangsabati River (also known as Kasai and Cossie). The climate follows a hot tropical monsoon weather pattern "Aw" (Tropical Savanna Climate) according to the Köppen Climate classification. According to the 2011 census, Midnapore municipality had a population of 169,264 .

The study area map is shown in Fig. 1 and the details of study area locations used for field data collection are summarized in table 1.

\begin{tabular}{|c|l|l|l|}
\hline \multicolumn{2}{|l}{ Asansol Town $\left(23.68^{\circ}\right.$ N, $86.99^{\circ}$ E; Elevation:111 $)$} \\
\hline Sr. No. & Station Name & Station Code & Category of Area \\
\hline 1. & Railway Hospital & RH & Silent Zone \\
\hline 2. & Asansol District Hospital & ADH & Silent Zone \\
\hline 3. & Sterling Nurshing Home & SNH & Silent Zone \\
\hline 4. & H.L.G Nurshing Home & HLG NH & Silent Zone \\
\hline 5. & Gurunanak Model School & GMS & Silent Zone \\
\hline 6. & Santi Nagar Vidya Mandir & SVM & Silent Zone \\
\hline 7. & Mohishila Boys Govt. High School & MBGHS & Silent Zone \\
\hline 8. & Monimala Girls High School & MGHS & Silent Zone \\
\hline 9. & Asansol Bus Stoppage (Inside ) & ABS (IN) & Commercial Zone \\
\hline 10. & Asansol Bus Stoppage ( Outside ) & ABS (OUT) & Commercial Zone \\
\hline 11. & Asansol Railway Station (Inside) & AS (IN) & Commercial Zone \\
\hline 12. & Asansol Railway Station ( Outside) & AS (OUT) & Commercial Zone \\
\hline 13. & Galaxy Mall & GM & Commercial Zone \\
\hline 14. & Sentrum Mall & SM & Commercial Zone \\
\hline 15. & G.T Road & GTR & Heavy Traffic Zone \\
\hline 16. & Court More & CM & Heavy Traffic Zone \\
\hline 17. & B.N.R More & BNRM & Heavy Traffic Zone \\
\hline 18. & Girja More & GM & Heavy Traffic Zone \\
\hline
\end{tabular}




\begin{tabular}{|c|c|c|c|}
\hline 19. & Bhagat Singh More & BSM & Heavy Traffic Zone \\
\hline 20. & S.D Hospital More & SDHM & Heavy Traffic Zone \\
\hline 21. & Indian Iron \& Steel Company & IISCO & Industrial Zone \\
\hline 22. & Kazi Nazrul University Indoor & KNU (IN) & University \\
\hline 23. & Kazi Nazrul University Outdoor & KNU (OUT) & University \\
\hline \multicolumn{4}{|c|}{ B. Bankura Town $\left(23.25^{\circ} \mathrm{N}, 87.07^{\circ} \mathrm{E}\right.$; Elevation:78 m) } \\
\hline Sr. No. & Sampling Location & Code & Zone \\
\hline 1. & $\begin{array}{l}\text { Bankura Sammilani Medical College And } \\
\text { Hospital }\end{array}$ & BSM & Silent Zone \\
\hline 2. & Mahamaya Nurshing Home & MNH & Silent Zone \\
\hline 3. & Anamay Nurshing Home & ANH & Silent Zone \\
\hline 4. & Bankura Nurshing Home & $\mathrm{BNH}$ & Silent Zone \\
\hline 5. & Jeevan Suraksha Hospital & $\mathrm{JSH}$ & Silent Zone \\
\hline 6. & Bankura Seva Niketan & BSN & Silent Zone \\
\hline 7. & Bankura Banga Vidyalaya & BBV & Silent Zone \\
\hline 8. & Mission Girls High School & MHS & Silent Zone \\
\hline 9. & Bankura Zilla School & BZS & Silent Zone \\
\hline 10. & Kenduadihi High School & KHS & Silent Zone \\
\hline 11. & Govindanagar Bus Stoppage & GNS & Commercial Zone \\
\hline 12. & College More & $\mathrm{CCM}$ & Commercial Zone \\
\hline 13. & Bankura Railway Station ( Inside) & BSI & Commercial Zone \\
\hline 14. & Bankura Railway Station ( Outside) & BSO & Commercial Zone \\
\hline 15. & Machantala & MCT & Commercial Zone \\
\hline 16. & Lalbazar & LB & Commercial Zone \\
\hline 17. & Katjuridanga More & KDM & Heavy Traffic Zone \\
\hline 18. & Dhaldanga More & DDM & Heavy Traffic Zone \\
\hline 19. & Nutanchati Bypass & NCB & Heavy Traffic Zone \\
\hline 20. & Poabagan More & PBM & Heavy Traffic Zone \\
\hline 21. & Satighat Bypass & SGB & Heavy Traffic Zone \\
\hline 22. & Machantala More & MTM & Heavy Traffic Zone \\
\hline 23. & Bankura University ( Indoor ) & BUI & Silent Zone \\
\hline 24. & Bankura University ( Outdoor ) & BUO & Silent Zone \\
\hline \multicolumn{4}{|c|}{ C. Mednipur Town $\left(22.25^{\circ} \mathrm{N}, 87.65^{\circ} \mathrm{E}\right.$; Elevation: $\left.23 \mathrm{~m}\right)$} \\
\hline Sr. No. & Sampling Location & Code & Zone \\
\hline 1. & Midnapore Medical College and Hospital & MMCH & Silent Zone \\
\hline 2. & Nirnoy Hospital & $\mathrm{NH}$ & Silent Zone \\
\hline 3. & Police Line Hospital & PLH & Silent Zone \\
\hline 4. & Spandan Nurshing Home & SNH & Silent Zone \\
\hline 5. & Mission Girls High School & MGHS & Silent Zone \\
\hline 6. & Aliganj Rishi Rajnarayan Girls School & ARRNGS & Silent Zone \\
\hline
\end{tabular}


Evaluation of Environmental Noise in Urban areas: A Noise Pollution Assessment Approach

\begin{tabular}{|c|l|l|l|}
\hline 7. & Vidyasagar Vidyapith Girls High School & VVGHS & Silent Zone \\
\hline 8. & Collegiate Girls High School & CGHS & Silent Zone \\
\hline 9. & Midnapore Bus Stoppage & MBS & Commercial Zone \\
\hline 10. & Midnapore Railway Station ( Inside) & MRS (IN) & Commercial Zone \\
\hline 11. & Midnapore Railway Station ( Outside) & MRS (OUT) & Commercial Zone \\
\hline 12. & Metro Bazar & MB & Commercial Zone \\
\hline 13. & Keranitola More & KM & Heavy Traffic Zone \\
\hline 14. & LIC More & LIC M & Heavy Traffic Zone \\
\hline 15. & Panchur Chak & PC & Heavy Traffic Zone \\
\hline 16. & Ashok Nagar More & ANM & Heavy Traffic Zone \\
\hline 17. & Subham Flat & SUF & Residential Zone \\
\hline 18. & Pragati Flat & PF & Residential Zone \\
\hline 19. & Suhasini Flat & SHF & Residential Zone \\
\hline 20. & Sriniketan Flat & SF & Residential Zone \\
\hline 21. & Vidyasagar University ( Inside ) & VU (IN) & Silent Zone \\
\hline 22. & Vidyasagar University ( Outside ) & VU (OUT) & Silent Zone \\
\hline
\end{tabular}

Table 1: Study Area Locations.

\section{Methodology}

A digital sound level meter, type 2 with frequency weighting network as per IEC651 specifications, the frequency range of $31.5 \mathrm{~Hz}$ to $8 \mathrm{kHz}$, and measuring range between $0-130 \mathrm{~dB}$ is used for the study. All readings were taken on the 'A-weighting frequency network, at a height of 1.5 meters from ground level and on the 'Fast' range Time Weighting. All measurements were carried out during working days and under suitable climatic conditions setting. The data were taken in different zones depending on the peak hours of traffic noise intensity. The variations of noise levels are assessed from the statistical distribution of noise intensity. The parameters used to evaluate and analysis of noise levels are L1, L5, L10, L50, L90, L95, L99, Leq (equivalent sound pressure level), Noise climate (NC), Lnp (Noise pollution level), Traffic Noise Index (TNI). L10, L50, L90, L95, and L99 respectively indicate the levels exceeded by 10\%, 50\%, 90\%, $95 \%$, and $99 \%$ of the time of a noise level in a given interval [23].

Equivalent Sound Pressure Level (Leq): It is the equivalent continuous noise level measured over a given period measured continuously at a particular point. It is measured by the equation:

$$
\text { Leq }=10 \log \left(\frac{1}{10} \sum_{i=1}^{n} 10^{\frac{L i}{10}}\right)
$$

Where $\mathrm{Li}$ is the $\mathrm{i}^{\text {th }}$ sound pressure level.

Noise Pollution Index (LNP)

LNP serves as an indicator of the pollution in the environment for physiological and psychological disturbance of the human body [23]. It is given by the equation:

$$
\text { Lnp }=\text { Leq }+ \text { L50+ (L10- L90) }
$$

\section{Noise climate (NC)}

Noise climate (NC) indicates the noise pollution level and is given by the relation [23]: 


$$
\text { Noise Climate }(\mathrm{NC})=(\mathrm{L} 10-\mathrm{L} 90)
$$

\section{Traffic Noise Index (TNI)}

Traffic noise index indicates the degree of variation or degree of annoyance in traffic flow and can be computed using the relation [23]:

$$
\mathrm{TNI}=4 \times(\mathrm{L} 10-\mathrm{L} 90)+(\mathrm{L} 90-30) \mathrm{dB}(\mathrm{A})
$$

\section{Results}

Nowadays, noise pollution has become a menace for people living in urban areas. Looking ahead the people still have not realized the harmfulness of this pollution. The present study reveals that the three cities Asansol, Bankura, and Midnapore, are very much affected by noise pollution and the scenario is deteriorating day by day on the long-term time scale. The noise data were collected from different study sites at different times to assess the changing noise level at various locations with a focus on Silent, Commercial, Residential and Industrial Zones on a long-term temporal scale. To understand the relationship and variations in noise intensity with climate, the study period is divided into pre-monsoon, Monsoon, and Post monsoon sessions. The time-series variations in the noise intensity are plotted to observe the variation in noise intensity in silent and commercial zones and in the pick traffic hours (Figure 2 to 5). The values are then compared with the standards (Table 2 and Table 3 ) to evaluate the noise pollution intensity. The analysis of the noise level of the three towns i.e Asansol, Bankura, and Midnapore are described below.

\begin{tabular}{|l|c|c|}
\hline \multirow{2}{*}{ Area Code } & \multicolumn{2}{|c|}{ Permissible Noise Limits in dB(A) Leq } \\
\cline { 2 - 3 } & Day (6 am to 9 pm) & Night (9pm to 6 am) \\
\hline Industrial Zone & 75 & 65 \\
\hline Commercial Zone & 65 & 55 \\
\hline Residential Zone & 55 & 45 \\
\hline Silent Zone & 45 & 35 \\
\hline Educational Institutions & 40 & 30 \\
\hline
\end{tabular}

Table 2: Permissible Noise in different types of location [Source: CPCB, 1998].

\begin{tabular}{|l|l|}
\hline $\boldsymbol{d B}(\boldsymbol{A})$ & Sensitivity \\
\hline $55-<60$ & Risky \\
\hline $60-<65$ & Moderately Risk \\
\hline $65-<70$ & Highly risky \\
\hline $70-<75$ & Dangerous \\
\hline $75-<80$ & Highly dangerous \\
\hline$>80$ & Extremely dangerous \\
\hline
\end{tabular}

Table 3: Noise sensitivity zones [Source, EPA].

\section{Asansol Town Noise Pollution Analysis}

Silent Zone Analysis

After monitoring continuously for three seasons, it is noticed that some silent zone of Asansol town is highly polluted by vehicular noise and other activities (Figure 2).

\section{Hospitals}

Asansol District hospital (ADH) and Railway hospital (RH) are beside the main road which is connected to Grand Trunk (GT) road. 
So the vehicular traffic is heavy throughout the day. Not only the people of Asansol but also the population of Durgapur and Purulia depends on these government and private hospitals. So the crowd is also responsible for the addition in this noise intensity. The HLG Nursing Home (HLG NH) is very close to the Kalyanpur Housing More which is a highly noise polluted area and hence highest noise intensity is recorded in this hospital. The Sterling Nursing Home (SNH) is also beside the main road which shows high noise intensity even after changing the measurement time and seasons. The noise intensity in all the hospital locations varies from $54 \mathrm{~dB}(\mathrm{~A})$ to 101 dB (A) (Figure 2).

\section{School}

Gurunanak Model School (GMS) shows low-level noise Intensity mostly between 44 to $55 \mathrm{~dB}$ (A), because of the absence of associated roads with traffic surrounding the school. Mohishila Boys Govt High School (MBGHS), Monimala Girls High School (MGHS), and Santinagar Vidyamandir (SVM) are surrounded by the main road and hence these schools suffer from heavy noise pollution during class hours (Figure 2).

\section{Kazi Nazrul University}

The town traffic does not affect the environment of Kazi Nazrul university as this university is around $4 \mathrm{Km}$ away from the main town. But as the university is at Kalla Hospital Road, beside the bypass road, the outside noise level hence sometimes shows a high pitch in the sound level meter due to sudden passing of the heavily loaded trucks and other vehicles. However, inside the campus noise intensity falls well within the standard limit, except for some sudden peaks which resulted from the construction works inside the campus (Figure 3).

\section{Commercial Zone}

The high noise pollution affected areas of the commercial zone are Asansol Bus Stoppage (ABS IN and ABS OUT) and Asansol Railway Station. As the bus service starts from 3.30 a.m every morning, therefore the noise pollution data shows high intensity mostly from the heavy rush hours i.e from 6 hrs to 11 hrs. The Galaxy Mall (GM) and Sentrum Mall (SM) is the main market of this town. The market opens after 9:30 am therefore the early morning the noise level is very low. The data taken after 10:00 a.m. shows the actual noise pollution level. The Railway station is connected by various roads and that is why the outside noise level also shows high pick data at all times. Asansol station is very busy with passing trains which result in higher intensity at the arrival and departure of trains (Figure 2).

\section{Heavy Traffic Zone}

Court More (CM) is among the highly polluted area as this junction is under NH 60. It is the connecting junction of various districts. Some small and big industries around the town are totally dependent on this junction for importing and exporting materials. Hence a large number of heavy trucks and buses passes through this junction which causes higher noise pollution. Even in the evening high average value of noise intensity is found ( $>85 \mathrm{~dB}$ ). BNR More (BNR M) is also the junction of various districts. So the data shows very high noise levels in the morning as well as in the evening. The Bhagat Singh More (BSM), Girja More (GM), S.D. Hospital More (SDHM) is also very busy with vehicles throughout the whole day. G.T. Road (GTR) is very much known to all due to its busy traffic. So it shows higher noise monitoring data during the whole day. As such no remarkable variations in the noise intensity are observed with different seasons (Figure 2). 


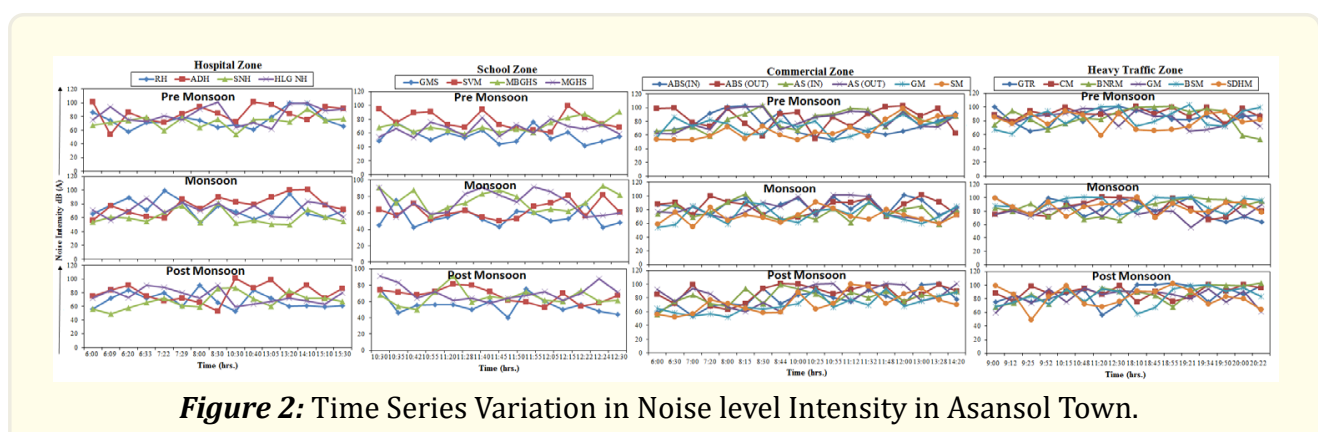

Figure 2: Time Series Variation in Noise level Intensity in Asansol Town.

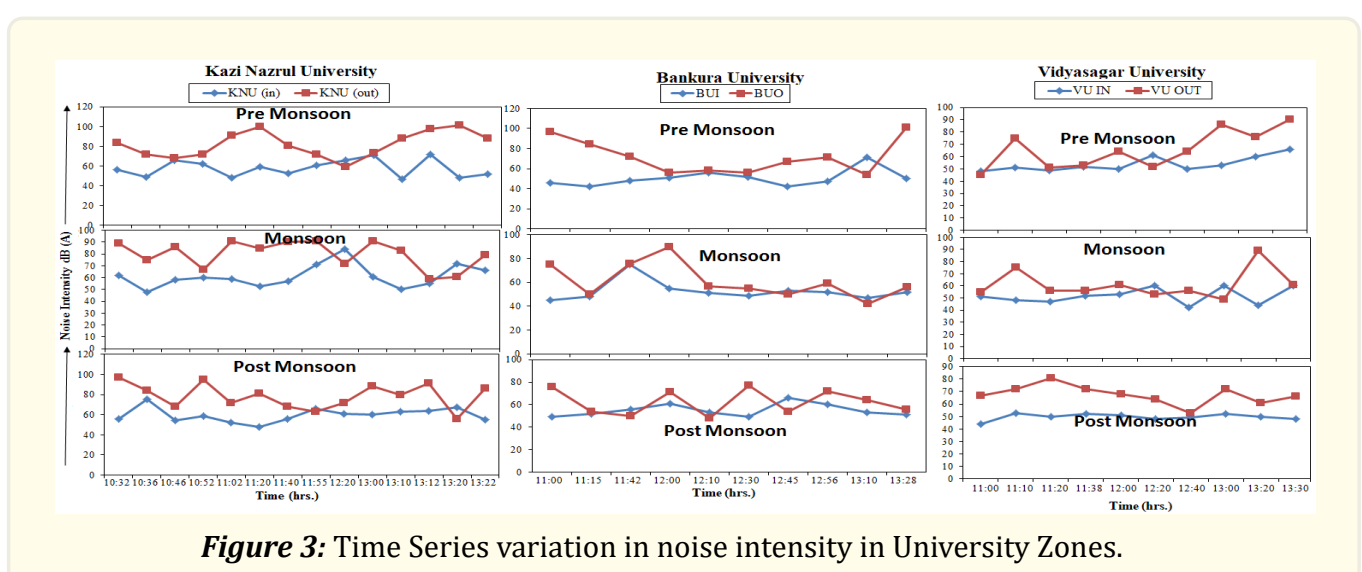

\section{Industrial Zone}

The Noise intensity outside the Indian Iron \& Steel Company (IISCO) is found to be higher particularly in pre and monsoon seasons, which cross the standard limits. However, the heavy traffic load associated with the connecting roads can be attributed to the rise in the noise intensity outside the industry (Figure 4).

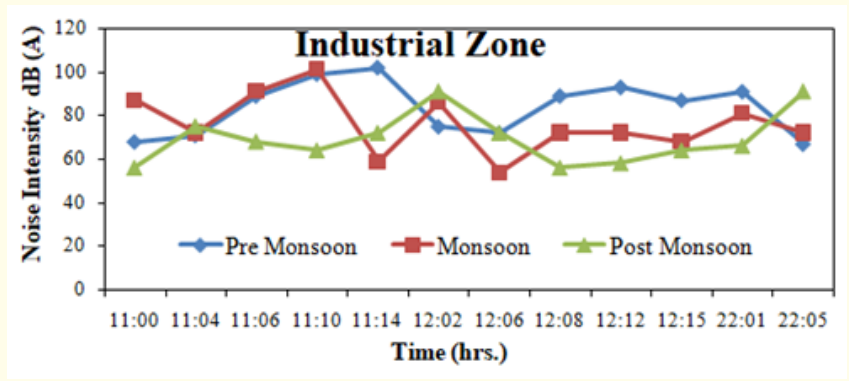

Figure 4: Variation of Noise Intensity in Industrial Zone.

The statistical analysis reveals the high level of noise pollution in all the zones. The Leq values in silent zones reveal all above the standard recommended levels. The commercial zones, the University zone also shows higher values than recommended levels (Table 4). However, the IISCO reports the noise pollution level much below the standard recommended levels, due to the adoption of proper 
Evaluation of Environmental Noise in Urban areas: A Noise Pollution Assessment Approach

noise controlling measures by the industry management. The Lnp (Noise pollution level) is much higher in the commercial, heavy traffic zone, and Kazi Nazrul University. The L1 values are also higher in commercial and heavy traffic zones. Traffic Noise Index (TNI) is recorded higher in both commercial and heavy traffic zones and also besides the hospitals and IISCO surrounding main road (Table 4).

\begin{tabular}{|c|c|c|c|c|c|c|c|c|c|c|c|}
\hline Location & Leq & $L 1$ & $L 5$ & $L 10$ & $L 50$ & $L 90$ & $L 95$ & $L 99$ & Lnp & $N C$ & TNI \\
\hline \multicolumn{12}{|c|}{ Hospital Zone,dB(A) } \\
\hline \multicolumn{12}{|c|}{ Premonsoon } \\
\hline$R H$ & 75.07 & 78.1 & 99.86 & 99.3 & 91 & 75 & 64.8 & 63.1 & 61.42 & 104.3 & 26.2 \\
\hline$A D H$ & 84.3 & 84.3 & 101 & 98.2 & 95.8 & 84.33 & 73.2 & 74.1 & 72.42 & 106.9 & 22.6 \\
\hline SNH & 72.5 & 72.4 & 89.32 & 82.6 & 78.6 & 75 & 61 & 61 & 55.4 & 90 & 17.6 \\
\hline HLG NH & 82.73 & 82.7 & 100.9 & 100.3 & 99.6 & 82.7 & 66.8 & 63.4 & 62.28 & 115.5 & 32.8 \\
\hline \multicolumn{12}{|c|}{ Monsoon } \\
\hline$R H$ & 73.5 & 98.4 & 96.2 & 92.6 & 71 & 58.8 & 56.5 & 53.7 & 107.3 & 33.8 & 164 \\
\hline$A D H$ & 78.3 & 100.9 & 100.3 & 96 & 79 & 72.4 & 72.7 & 72.14 & 101.9 & 23.6 & 136.8 \\
\hline SNH & 60.3 & 80.44 & 78.2 & 75 & 60.3 & 51.4 & 50.7 & 50.14 & 83.9 & 23.6 & 115.8 \\
\hline HLG NH & 71.6 & 87.44 & 85.2 & 83.2 & 71.6 & 61.4 & 60.7 & 60.14 & 93.4 & 21.8 & 118.6 \\
\hline \multicolumn{12}{|c|}{ Post Monsoon } \\
\hline$R H$ & 68.7 & 90.02 & 86.1 & 84 & 68.7 & 59.4 & 57.2 & 53.84 & 93.3 & 24.6 & 127.8 \\
\hline$A D H$ & 79.7 & 100.7 & 99.6 & 95.8 & 79.7 & 66.8 & 62.1 & 54.82 & 108.7 & 29 & 152.8 \\
\hline SNH & 67.9 & 86.86 & 86.3 & 84.8 & 71 & 60.4 & 59.7 & 59.14 & 92.3 & 24.4 & 128 \\
\hline HLG NH & 74.9 & 91 & 91 & 89.8 & 74.8 & 63 & 61.8 & 59.56 & 101.7 & 26.8 & 140.2 \\
\hline \multicolumn{12}{|c|}{ Schools Zone, $d B(A)$} \\
\hline \multicolumn{12}{|c|}{ Premonsoon } \\
\hline GMS & 72.8 & 73.4 & 92 & 92 & 88.4 & 73.38 & 60.6 & 61.8 & 59.56 & 101.2 & 27.8 \\
\hline$S V M$ & 77.93 & 76.79 & 98.44 & 95.5 & 92.8 & 73 & 64.8 & 63.1 & 61.42 & 104.8 & 28 \\
\hline MBGHS & 70.67 & 70.84 & 90.58 & 88.9 & 85.6 & 70.67 & 61 & 60.4 & 61 & 95.44 & 24.6 \\
\hline MGHS & 66.07 & 66.87 & 81.86 & 81.3 & 79 & 68 & 57.2 & 55.7 & 55.56 & 88.67 & 21.8 \\
\hline \multicolumn{12}{|c|}{ Monsoon } \\
\hline GMS & 67.13 & 66.87 & 89.74 & 84.7 & 78 & 67.14 & 60.6 & 57.8 & 59.56 & 84.27 & 17.4 \\
\hline$S V M$ & 62.93 & 62.86 & 81.86 & 81.3 & 77.4 & 62.86 & 53.8 & 52.1 & 50.42 & 86.42 & 23.6 \\
\hline MBGHS & 75.46 & 74.43 & 92.72 & 89.5 & 88 & 74.43 & 63.2 & 61.7 & 61.14 & 99.23 & 24.8 \\
\hline MGHS & 72.67 & 71.44 & 91.86 & 91.3 & 89 & 73 & 58.2 & 56.4 & 55.28 & 102.2 & 30.8 \\
\hline \multicolumn{12}{|c|}{ Post Monsoon } \\
\hline$A B S(O U T)$ & 73 & 73 & 85.74 & 84.6 & 84 & 73 & 59.4 & 57.2 & 53.84 & 97.6 & 24.6 \\
\hline$A S(I N)$ & 67.14 & 67.14 & 80.87 & 80.3 & 76.8 & 67.14 & 55.6 & 53.7 & 53.14 & 88.34 & 21.2 \\
\hline$A S$ (OUT) & 65 & 65 & 88.66 & 78.4 & 72.6 & 65 & 60 & 59.7 & 59.14 & 77.6 & 12.6 \\
\hline MGHS & 70.43 & 70.43 & 90.61 & 88.9 & 78.6 & 70 & 61 & 60.1 & 58.42 & 88.03 & 17.6 \\
\hline \multicolumn{12}{|c|}{ Commercial Zone, $d B(A)$} \\
\hline \multicolumn{12}{|c|}{ Premonsoon } \\
\hline$A B S(I N)$ & 76.66 & 102.7 & 101.6 & 93.2 & 72 & 59.2 & 56.5 & 53.7 & 110.7 & 34 & 165.2 \\
\hline$A B S(O U T)$ & 83.4 & 102.7 & 101.6 & 100.2 & 88 & 67 & 60.6 & 56.12 & 116.6 & 33.2 & 169.8 \\
\hline
\end{tabular}


Evaluation of Environmental Noise in Urban areas: A Noise Pollution Assessment Approach

\begin{tabular}{|c|c|c|c|c|c|c|c|c|c|c|c|}
\hline$A S(I N)$ & 84.47 & 103.3 & 100.5 & 98.2 & 88 & 72.4 & 71.2 & 73.56 & 110.2 & 25.8 & 145.6 \\
\hline$A S$ (OUT) & 85.27 & 101.8 & 101.3 & 98.6 & 86 & 72 & 72 & 72 & 111.8 & 26.6 & 148.4 \\
\hline \multicolumn{12}{|c|}{ Monsoon } \\
\hline$A B S(I N)$ & 86.13 & 100.8 & 100.3 & 99.6 & 86.13 & 72 & 72 & 72 & 113.7 & 27.6 & 152.4 \\
\hline$A B S(O U T)$ & 84 & 100.8 & 98.2 & 94.6 & 84 & 69.4 & 69.7 & 70.28 & 109.2 & 25.2 & 140.2 \\
\hline$A S(I N)$ & 77 & 101.3 & 94.6 & 88.6 & 77 & 62.2 & 60.4 & 59.28 & 103.4 & 26.4 & 137.8 \\
\hline$A S(O U T)$ & 80.73 & 101 & 101 & 100.2 & 82 & 67.2 & 64.2 & 60.84 & 113.7 & 33 & 169.2 \\
\hline \multicolumn{12}{|c|}{ Post Monsoon } \\
\hline$A B S(I N)$ & 81.73 & 100.7 & 99.6 & 97 & 83 & 73.2 & 74.1 & 72.42 & 105.5 & 23.8 & 138.4 \\
\hline$A B S(O U T)$ & 87.6 & 100.8 & 100.3 & 99.6 & 94 & 85.4 & 81.7 & 75.54 & 101.8 & 14.2 & 112.2 \\
\hline$A S(I N)$ & 83 & 98.3 & 95.5 & 93.6 & 84 & 77.6 & 74.5 & 71.7 & 99 & 16 & 111.6 \\
\hline$A S$ (OUT) & 84.13 & 101 & 101 & 101 & 91 & 76 & 76 & 76 & 109.1 & 25 & 146 \\
\hline \multicolumn{12}{|c|}{ Heavy Traffic Zone, $d B(A)$} \\
\hline \multicolumn{12}{|c|}{ Premonsoon } \\
\hline GTR & 84.9 & 100.6 & 98.9 & 97.6 & 87 & 79.8 & 79.2 & 75.84 & 102.7 & 17.8 & 121 \\
\hline$C M$ & 73.73 & 98.86 & 98.3 & 93.2 & 73.73 & 60.2 & 57.2 & 53.84 & 106.7 & 33 & 162.2 \\
\hline BNRM & 85.06 & 100.8 & 100.3 & 99.6 & 93 & 68.2 & 57.2 & 53.84 & 116.4 & 31.4 & 163.8 \\
\hline$G M$ & 82.93 & 97.86 & 97.3 & 96.6 & 86 & 69 & 66.4 & 65.28 & 110.5 & 27.6 & 149.4 \\
\hline \multicolumn{12}{|c|}{ Monsoon } \\
\hline GTR & 82.73 & 100.7 & 99.6 & 99 & 82.73 & 66.4 & 64 & 64 & 115.3 & 32.6 & 166.8 \\
\hline$C M$ & 84.86 & 100.7 & 100.3 & 99.6 & 88 & 71.4 & 69.8 & 67.56 & 113.0 & 28.2 & 154.2 \\
\hline BNRM & 86.13 & 100.6 & 98.9 & 97.6 & 90 & 69.6 & 70.2 & 68.8 & 114.1 & 28 & 151.6 \\
\hline$G M$ & 80.13 & 95.72 & 94.6 & 92.8 & 80.13 & 72 & 67.2 & 58.24 & 100.9 & 20.8 & 125.2 \\
\hline \multicolumn{12}{|c|}{ Post Monsoon } \\
\hline GTR & 87.2 & 102.7 & 101.6 & 101 & 93 & 73.2 & 67.2 & 72.42 & 115 & 27.8 & 154.4 \\
\hline$C M$ & 84.93 & 101 & 101 & 100.2 & 90 & 75.4 & 75.7 & 75.14 & 109.7 & 24.8 & 144.6 \\
\hline BNRM & 88.26 & 102.7 & 101.6 & 100.6 & 91 & 79 & 79.9 & 70.38 & 109.8 & 21.6 & 135.4 \\
\hline$G M$ & 84.6 & 95.72 & 94.6 & 94 & 86 & 77 & 70.8 & 62.96 & 101.6 & 17 & 115 \\
\hline \multicolumn{12}{|c|}{ KaziNazrul University, $d B(A)$} \\
\hline \multicolumn{12}{|c|}{ Premonsoon } \\
\hline$K N U$ (in) & 57.8 & 71.9 & 71.3 & 69 & 59 & 48 & 47.7 & 47.1 & 78.9 & 21 & 102 \\
\hline KNU (out) & 81.9 & 100.9 & 100.3 & 99.2 & 81.93 & 72 & 68.1 & 60.8 & 109.2 & 27.2 & 150.8 \\
\hline \multicolumn{12}{|c|}{ Monsoon } \\
\hline$K N U$ (in) & 61.14 & 82.44 & 75.6 & 71.6 & 61 & 53.8 & 52.1 & 50.4 & 78.9 & 17.8 & 95 \\
\hline KNU (out) & 79.93 & 91 & 91 & 91 & 83 & 63.4 & 60.4 & 59.2 & 107.5 & 27.6 & 143.8 \\
\hline \multicolumn{12}{|c|}{ Post Monsoon } \\
\hline KNU (in) & 59.71 & 73.96 & 69.4 & 66.6 & 59.71 & 53.2 & 50.8 & 48.9 & 73.11 & 13.4 & 76.8 \\
\hline KNU (out) & 78.64 & 96.74 & 95.6 & 89.8 & 78.64 & 65 & 60.9 & 56.9 & 103.4 & 24.8 & 134.2 \\
\hline \multicolumn{12}{|c|}{ IISCO } \\
\hline \multicolumn{12}{|c|}{ Premonsoon } \\
\hline IISCO & 85.07 & 101.7 & 100.6 & 99.6 & 89 & 73.2 & 70.5 & 67.7 & 111.5 & 26.4 & 148.8 \\
\hline
\end{tabular}




\begin{tabular}{|c|c|c|c|c|c|c|c|c|c|c|c|}
\hline \multicolumn{12}{|c|}{ Monsoon } \\
\hline IISCO & 76.25 & 99.9 & 95.5 & 90.5 & 74.12 & 59.9 & 61.7 & 55.5 & 106.8 & 30.6 & 152.3 \\
\hline \multicolumn{12}{|c|}{ Post Monsoon } \\
\hline IISCO & 69.42 & 91 & 91 & 89.1 & 69.42 & 58.6 & 57.1 & 56.2 & 99.9 & 30.5 & 150.6 \\
\hline
\end{tabular}

Table 4: Different indices for estimating the Noise Pollution in Asansol Town.

\section{Bankura Town Noise Pollution Analysis}

Silent Zone Analysis

Hospitals

Sammilani Medical College and Hospital (BSM) are the main government hospital in this town. A road with heavy traffic passes adjacent to this hospital. Besides, a taxi stand and auto-rickshaws stand are also situated adjacent to this hospital. Hence during the day, the noise pollution level is much high as revealed from different recording times in the different seasons. People from the whole district and also from the other neighboring districts like Purulia and Burdwan are highly dependent on this medical college for its modern technological facilities. Hence, a huge number of patients visit this hospital, and the noise level is always very high. The Bankura Seva Niketan (BSN) is beside the main road and the noise level of that area is also high throughout the day. Anamoy Nursing home (ANH) is very close to the Bankura Govindanagar Central bus stoppage and it is also a high alert zone of sound pollution. Other hospitals are not beside the road and so the noise level recorded is found to be average, however, in all these hospitals noise intensity is found much above the standard limit (Figure 5).

Schools

The three schools Banga Vidyalaya (BVB), Zilla School (BZS), and Mission Girls High School (MGS) are in the central of the town and beside the main road. So throughout the day and especially at the time of classes, the schools are highly affected by noise pollution. The use of a microphone and soundbox for religious and marriage purposes is the big reason for such high noise intensity even sometimes an average data of $102 \mathrm{~dB}$ is recorded beside Bankura Zilla School (BZS) and $97 \mathrm{~dB}$ beside Banga Vidyalaya (BBV) (Figure 5).

\section{Bankura University}

The town traffic does not affect the university since the university is $7 \mathrm{~km}$ away from the main town. But the campus of the university is situated beside NH 60; hence the outside noise level shows, sometimes, high pitch in sound level meter during the passage of heavily loaded trucks and other vehicles. The university is stretched over a large area; hence, the sound level meter shows the low average and somewhere little high average data where constructional works are in progress. A little bit of low noise intensity measurement is seen in the monsoon session (Figure 2).

\section{Commercial Zone Analysis}

The Govindanagar central bus stoppage (GBS) is the main highly busy bus stoppage of this town. Bus service starts from 3.30 am hence at 6 am the area is highly polluted by noises from horns and engines. The Lalbazar (LB) and Machantala (MC) is the main market of Bankura town. The market opens at around 9:00 am. Hence during the early morning hours, the noise intensity is not very high. As the Bankura station is beside the main road, the noise level is high outside the railway station. But inside the station, there is an average noise data recorded except during the arrival and departure of the trains. The College More (CM) is also a market complex of this town, and so there is fluctuation in measured noise Intensity (Figure 5).

\section{Heavy traffic Zone Analysis}

Dhaldanga More (DDM) is a highly noise polluted area that is under NH 60. It is a junction of various roads running to various dis- 
tricts connected to Bankura town. There are also some small and big industries situated beside Bankura town which are dependent on this junction. The main industrial area of Durgapur is also totally dependent on this junction. Hence, a large number of heavy trucks and busses pass through this junction and make this area highly polluted. From the evening data of heavy traffic zone, it reveals a high average ( $>85 \mathrm{~dB}$ ) noise intensity. The Poabagan More (PM) is also a highly noise polluted area of this town. It is also the junction of various districts and various industries. So, in the morning as well as in the evening, the data recorded are very high. The other four junctions like Machantala More (MM), Katjuridanga More (KM), Nutanchati Bypass (NB), and Satighat Bypass (SB) are also very vital junction, and the noise level average is much higher in the morning rather than in the evening. As such no such variation is observed in Pre-Post and Monsoon Seasons (Figure 5).

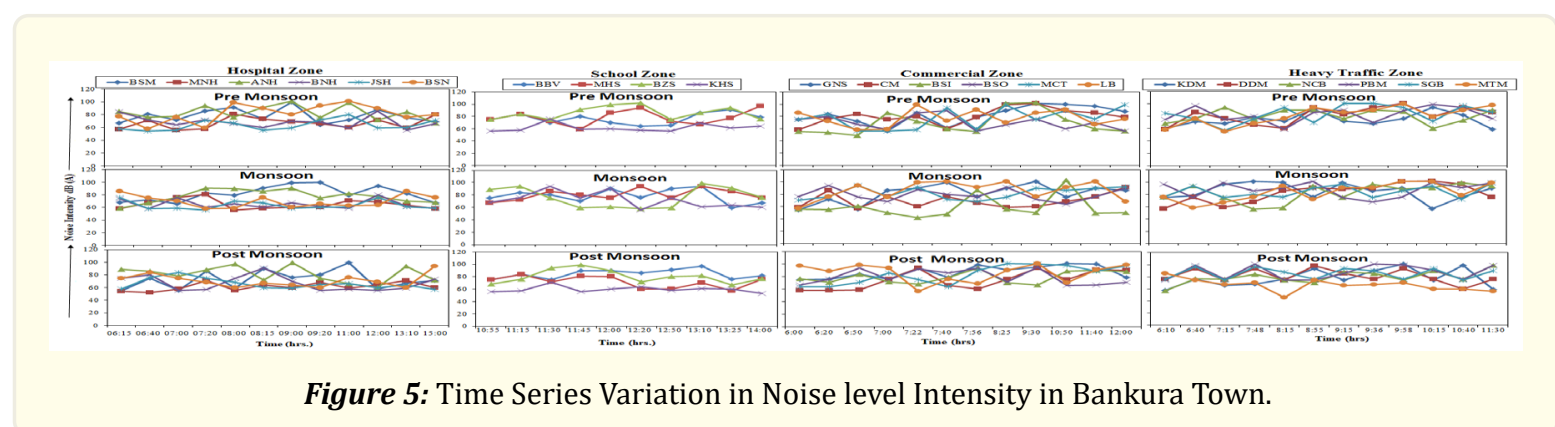

The Leq values reveal much higher than the recommended value in silent zones. Traffic Noise Index (TNI) is recorded higher in all the locations. Noise Pollution Index (LNP) is also higher in all locations (Table 5).

\begin{tabular}{|c|c|c|c|c|c|c|c|c|c|c|c|}
\hline Location & Leq & $L 1$ & $L 5$ & $L 10$ & $L 50$ & $L 90$ & $L 95$ & $L 99$ & Lnp & $N C$ & TNI \\
\hline \multicolumn{12}{|c|}{ Hospital Zone,dB(A) } \\
\hline \multicolumn{12}{|c|}{ Premonsoon } \\
\hline$B S M$ & 78.1 & 99.0 & 94.6 & 90.1 & 78.2 & 70.2 & 67.5 & 64.7 & 98.1 & 19.9 & 119.8 \\
\hline MNH & 66.8 & 80.9 & 80.4 & 77.9 & 66.8 & 58.4 & 57.4 & 58.1 & 86.3 & 19.5 & 106.4 \\
\hline ANH & 83.0 & 100.8 & 99.8 & 97.5 & 83.0 & 73.2 & 70.5 & 67.7 & 107.3 & 24.3 & 140.4 \\
\hline$B N H$ & 68.6 & 85.78 & 84.8 & 80.4 & 68.6 & 59.4 & 58.1 & 56.42 & 89.6 & 21 & 113.4 \\
\hline JSH & 63.6 & 79.12 & 75.2 & 71.7 & 63.6 & 56 & 56 & 56.42 & 79.3 & 15.7 & 88.8 \\
\hline$B S N$ & 81.6 & 100.8 & 99.8 & 97.5 & 81.7 & 65.8 & 70.9 & 61.4 & 113.3 & 31.7 & 162.6 \\
\hline \multicolumn{12}{|c|}{ Monsoon } \\
\hline$B S M$ & 81.6 & 99.89 & 99.4 & 97.5 & 81.6 & 69 & 66.7 & 68.68 & 110.1 & 28.5 & 153 \\
\hline$M N H$ & 64.9 & 80.4 & 78 & 74.5 & 64.9 & 58.4 & 57.4 & 56.28 & 81.0 & 16.1 & 92.8 \\
\hline$A N H$ & 77.6 & 91 & 91 & 90.7 & 77.6 & 68.8 & 69.4 & 68.28 & 99.6 & 21.9 & 126.4 \\
\hline$B N H$ & 65.2 & 79.6 & 77.6 & 75.4 & 65.3 & 59 & 59 & 59 & 81.6 & 16.4 & 94.6 \\
\hline JSH & 63.5 & 76 & 76 & 74.2 & 61 & 58.4 & 58.1 & 56.4 & 79.3 & 15.8 & 91.6 \\
\hline$B S N$ & 69.9 & 86 & 86 & 83 & 69.9 & 59.4 & 58.7 & 58.1 & 93.5 & 23.6 & 123.8 \\
\hline \multicolumn{12}{|c|}{ Post Monsoon } \\
\hline BSM & 72.6 & 98.01 & 93.6 & 88.8 & 72.7 & 58.4 & 57.4 & 58.14 & 103.7 & 30.4 & 150 \\
\hline$M N H$ & 61.4 & 71 & 71 & 70.1 & 61.4 & 56.8 & 57.4 & 56.42 & 74.7 & 13.3 & 80 \\
\hline
\end{tabular}


Evaluation of Environmental Noise in Urban areas: A Noise Pollution Assessment Approach

\begin{tabular}{|c|c|c|c|c|c|c|c|c|c|c|c|}
\hline ANH & 81.3 & 98.8 & 97.8 & 96.1 & 81.3 & 68.4 & 64.2 & 60.8 & 109.0 & 27.7 & 149.2 \\
\hline$B N H$ & 67.2 & 89.8 & 84.4 & 78.5 & 67.2 & 56 & 56 & 56 & 89.6 & 22.5 & 116 \\
\hline$J S H$ & 66 & 83.1 & 79.2 & 75.7 & 66 & 59.4 & 58.4 & 57.3 & 82.3 & 16.3 & 94.6 \\
\hline$B S N$ & 71 & 92.9 & 88 & 81.6 & 71 & 60 & 60 & 60 & 92.6 & 21.6 & 116.4 \\
\hline \multicolumn{12}{|c|}{ Schools Zone, $d B(A)$} \\
\hline \multicolumn{12}{|c|}{ Premonsoon } \\
\hline$B B V$ & 77.1 & 117.1 & 102.5 & 90 & 77.13 & 67.2 & 65.4 & 64.3 & 99.9 & 22.8 & 128.4 \\
\hline MHS & 76.6 & 105.3 & 100.7 & 96.4 & 76.5 & 68.5 & 64.6 & 60.12 & 104.4 & 27.9 & 150.1 \\
\hline$B Z S$ & 86.8 & 136.4 & 117.4 & 101.4 & 86.8 & 75 & 75 & 75 & 113.2 & 26.4 & 150.6 \\
\hline KHS & 64.7 & 110.5 & 90.9 & 74.6 & 61 & 56.6 & 56 & 56.28 & 82.7 & 18 & 98.6 \\
\hline \multicolumn{12}{|c|}{ Monsoon } \\
\hline$B B V$ & 78.5 & 93.6 & 92 & 90 & 78.5 & 67.9 & 64.6 & 60.12 & 100.6 & 22.1 & 126.3 \\
\hline MHS & 84.3 & 147.8 & 117.6 & 94 & 84.2 & 72.9 & 70.5 & 72.42 & 105.3 & 21.1 & 127.3 \\
\hline$B Z S$ & 73.14 & 98.4 & 96 & 93.76 & 75 & 59 & 58.7 & 58.14 & 107.9 & 34.76 & 168.0 \\
\hline KHS & 74.4 & 123.2 & 106.9 & 93.4 & 74.4 & 60.3 & 58.8 & 56.56 & 107.6 & 33.1 & 162.7 \\
\hline \multicolumn{12}{|c|}{ Post Monsoon } \\
\hline$B B V$ & 84.6 & 96.46 & 94 & 90.9 & 84.6 & 75.3 & 75 & 75.14 & 100.2 & 15.6 & 107.7 \\
\hline MHS & 76.8 & 144.4 & 110.4 & 83.4 & 76 & 60 & 59.1 & 57.42 & 100.2 & 23.4 & 123.6 \\
\hline BZS & 74.8 & 98.4 & 96 & 93.2 & 77 & 69.2 & 67.7 & 67.7 & 98.8 & 24 & 135.2 \\
\hline KHS & 67.8 & 144.4 & 102.3 & 70.4 & 60 & 56 & 55.1 & 53.42 & 82.2 & 14.4 & 83.5 \\
\hline \multicolumn{12}{|c|}{ Commercial Zone, $d B(A)$} \\
\hline \multicolumn{12}{|c|}{ Premonsoon } \\
\hline GNS & 82.4 & 100.9 & 100.4 & 99.1 & 84 & 65.4 & 59.5 & 56.7 & 116.1 & 33.7 & 170.2 \\
\hline$C M$ & 80.6 & 100.8 & 99.8 & 96.3 & 80.6 & 75.4 & 70.5 & 62.1 & 101.4 & 20.9 & 129 \\
\hline BSI & 73.75 & 102.8 & 101.8 & 97.7 & 73.75 & 57.2 & 56 & 56 & 114.2 & 40.5 & 189.2 \\
\hline BSO & 70.1 & 89.6 & 87.6 & 84.2 & 70.0 & 57.2 & 56 & 56 & 97.1 & 27 & 135.2 \\
\hline MCT & 76.75 & 99 & 99 & 97.5 & 76.75 & 56.8 & 56 & 56.28 & 117.4 & 40.7 & 189.6 \\
\hline$L B$ & 77.3 & 98.1 & 94.2 & 91 & 77.3 & 62.2 & 58.7 & 60.1 & 106.1 & 28.8 & 147.4 \\
\hline \multicolumn{12}{|c|}{ Monsoon } \\
\hline GNS & 81.2 & 100.8 & 99.8 & 96.3 & 86 & 73.2 & 69.3 & 75.14 & 104.4 & 23.1 & 135.6 \\
\hline$C M$ & 69.5 & 90.45 & 88 & 83 & 69.5 & 59.4 & 58.4 & 59.14 & 93.1 & 23.6 & 123.8 \\
\hline$B S I$ & 69 & 93.1 & 89.2 & 86 & 69 & 56.6 & 57.5 & 54.7 & 98.4 & 29.4 & 144.2 \\
\hline BSO & 79.1 & 93.67 & 92.2 & 90.7 & 79.2 & 69.6 & 66.8 & 64.6 & 100.3 & 21.1 & 124 \\
\hline MCT & 81.7 & 93.8 & 92.8 & 91.7 & 81.7 & 73.2 & 70.8 & 68.6 & 100.2 & 18.5 & 117.2 \\
\hline$L B$ & 85.8 & 101 & 101 & 101 & 91 & 75.4 & 72.9 & 68.98 & 111.4 & 25.6 & 147.8 \\
\hline \multicolumn{12}{|c|}{ Post Monsoon } \\
\hline GNS & 87.4 & 100.9 & 100.4 & 99.7 & 87.4 & 77.2 & 78.1 & 76.42 & 109.9 & 22.5 & 137.2 \\
\hline$C M$ & 76.2 & 94 & 94 & 93.4 & 76.14 & 61.8 & 59.7 & 60.84 & 107.8 & 31.6 & 158.2 \\
\hline BSI & 79.1 & 93.6 & 91.6 & 89.7 & 79.1 & 68.8 & 67.7 & 67.14 & 99.9 & 20.9 & 122.4 \\
\hline BSO & 79.5 & 94.89 & 94.4 & 94 & 79.6 & 68.6 & 66.7 & 66.14 & 104.9 & 25.4 & 140.2 \\
\hline
\end{tabular}


Evaluation of Environmental Noise in Urban areas: A Noise Pollution Assessment Approach

\begin{tabular}{|c|c|c|c|c|c|c|c|c|c|c|c|}
\hline MCT & 83.3 & 100.9 & 100.4 & 99.4 & 86 & 66.8 & 68.9 & 65.54 & 115.8 & 32.6 & 167.2 \\
\hline$L B$ & 86 & 100.9 & 99.8 & 99 & 90 & 69.4 & 65.4 & 58.7 & 115.6 & 29.6 & 157.8 \\
\hline \multicolumn{12}{|c|}{ Heavy Traffic Zone, $d B(A)$} \\
\hline \multicolumn{12}{|c|}{ Premonsoon } \\
\hline$K D M$ & 74.3 & 93.67 & 92.2 & 88.3 & 74.3 & 68 & 65.3 & 60.3 & 94.5 & 20.3 & 119.2 \\
\hline$D D M$ & 81.5 & 100.2 & 96.8 & 94 & 83 & 70 & 64.2 & 60.8 & 105.5 & 24 & 136 \\
\hline$N C B$ & 78.3 & 93.6 & 91.6 & 90 & 78.3 & 65.2 & 59.4 & 58.3 & 103.1 & 24.8 & 134.4 \\
\hline$P B M$ & 82.5 & 98.78 & 97.8 & 96.1 & 82.5 & 72 & 66.7 & 60.54 & 106.6 & 24.1 & 138.4 \\
\hline$S G B$ & 84.1 & 101 & 101 & 99.8 & 85 & 70.8 & 66.1 & 70.28 & 113.1 & 29 & 156.8 \\
\hline MTM & 80.8 & 99.78 & 98.8 & 96.8 & 80.9 & 71.2 & 64.1 & 69.12 & 106.4 & 25.6 & 143.6 \\
\hline \multicolumn{12}{|c|}{ Monsoon } \\
\hline$K D M$ & 85.4 & 100.9 & 100.4 & 99.7 & 86 & 76 & 70.3 & 59.7 & 109.1 & 23.7 & 140.8 \\
\hline$D D M$ & 82.7 & 101.9 & 101.4 & 99.8 & 86 & 71.2 & 65.3 & 69.12 & 111.2 & 28.6 & 155.6 \\
\hline$N C B$ & 83.2 & 98.8 & 97.8 & 96.1 & 89 & 64.8 & 57.4 & 56.28 & 114.5 & 31.3 & 160 \\
\hline$P B M$ & 88.9 & 100.9 & 100.4 & 99.7 & 90 & 75 & 72.9 & 68.9 & 112.8 & 24.7 & 143.8 \\
\hline$S G B$ & 84.5 & 98.78 & 97.8 & 96.1 & 84.5 & 75 & 74.1 & 72.42 & 105.6 & 21.1 & 129.4 \\
\hline MTM & 83.7 & 101 & 101 & 100.4 & 83.75 & 69 & 70.5 & 72.56 & 115.1 & 31.4 & 164.6 \\
\hline \multicolumn{12}{|c|}{ Post Monsoon } \\
\hline$K D M$ & 78.1 & 100.8 & 99.8 & 97.5 & 76 & 66.8 & 63.9 & 60.3 & 108.7 & 30.7 & 159.6 \\
\hline$D D M$ & 81.7 & 97.6 & 95.6 & 94 & 81.7 & 75 & 70.5 & 62.1 & 100.6 & 19 & 121 \\
\hline$N C B$ & 79.4 & 98.01 & 93.6 & 89.4 & 79.4 & 75 & 73.5 & 70.7 & 93.8 & 14.4 & 102.6 \\
\hline$P B M$ & 87.8 & 101 & 101 & 100.7 & 87.8 & 75.4 & 75 & 75 & 113.1 & 25.3 & 146.6 \\
\hline$S G B$ & 85.7 & 97 & 97 & 96.1 & 88 & 75.4 & 75 & 75.14 & 106.4 & 20.7 & 128.2 \\
\hline MTM & 66.5 & 84.79 & 79.4 & 75 & 67 & 57.6 & 53 & 47.4 & 83.9 & 17.4 & 97.2 \\
\hline \multicolumn{12}{|c|}{ BankuraUniversity, $d B(A)$} \\
\hline \multicolumn{12}{|c|}{ Premonsoon } \\
\hline$B U I$ & 55.4 & 70.01 & 65.5 & 59.7 & 55.4 & 49.3 & 49 & 49 & 65.8 & 10.4 & 60.9 \\
\hline BUO & 71.6 & 100.6 & 99 & 95.7 & 71.6 & 56 & 55.4 & 54.3 & 111.3 & 39.7 & 184.8 \\
\hline \multicolumn{12}{|c|}{ Monsoon } \\
\hline$B U I$ & 54.5 & 70.92 & 66 & 59.45 & 54 & 50.3 & 48.8 & 46.56 & 63.65 & 9.15 & 56.9 \\
\hline BUO & 67.4 & 89.46 & 87 & 83.2 & 67.4 & 55.3 & 53.5 & 50.7 & 95.3 & 27.9 & 136.9 \\
\hline \multicolumn{12}{|c|}{ Post Monsoon } \\
\hline BUI & 55 & 65.55 & 63.5 & 60.9 & 55 & 49.6 & 49 & 49.3 & 66.3 & 11.3 & 64.8 \\
\hline BUO & 62.2 & 76.91 & 76.5 & 75.6 & 62.2 & 51.2 & 49.4 & 48.3 & 86.6 & 24.4 & 118.8 \\
\hline
\end{tabular}

Table 5: Different indices for estimating the Noise Pollution inBankura Town. 
Midnapore Town Noise Pollution Analysis

Silent Zone Analysis

Hospitals

The Midnapore medical college and hospital (MMCH) and Nirnoy Hospital (NH) both are beside the main road of the town. Although there is a medical college in east Midnapore and Jhargram district, for the better facility and easy transportation, the people of those two districts highly depend on the medical college of Midnapore. So the noise intensity is always high due to vehicular transportation and heavy crowds. The patients of the wards beside the main road are always being the victim of high noise exposure. The buses, motorbikes, and autorickshaws unnecessarily blow their horns without the knowledge of the hospital zone as a sensitive zone. The other two hospitals i.e Police line Hospital (PLH) and Spandan Nursing Home (SNH) are away from the main busy road. So average noise levels recorded at these places are low; compared to the other two. However, the Noise intensity in all these locations is above the standard limit for the silent zones (Figure 6).

\section{Schools}

The three schools like Vidyasagar Vidyapith Girls high School (VVGHS), Aliganj Rishi Rajnarayan School (ARRNGS), and Collegiate Girls High School (CGHS) are situated inside of the town, and a few vehicles passed by the road beside the school. Hence these schools are sometimes affected by noise pollution. But Mission Girls High School (MGHS) is beside the main road and the noise level shows high during school time. In the post-monsoon season, however, slight low noise intensity is observed compared to the pre and monsoon seasons.

\section{Vidyasagar University}

The University is about $3.5 \mathrm{~km}$ away from the main town. So the town traffic is not affected by the university environment. Also due to the vast area of the university campus and the presence of various trees, the noise level shows very low intensity even sometimes $42 \mathrm{~dB}$ average inside the university. But as a road passes beside the university, the sound level shows sometimes high outside the university (Figure 2).

\section{Commercial Zone Analysis}

The entire four commercial zones taken in this data are at an extremely high level of noise pollution. As the bus service starts from 3.15 a.m, the Midnapore Bus Stoppage (MBS) always shows high noise intensity from 6 a.m onwards. Uses of horns and the engine sound of various vehicles are the main reason behind this. Inside the Midnapore Railway Station (MRS IN) high noise graph shows only the time of arrival and departure of trains' otherwise average noise level recorded inside. But in the case of the outside of the railway station (MRS OUT), due to a connection of high road, high range noise data were seen in the morning. Although Metro Bazar (MB) shopping mall opens at around 11 a.m, the fluctuation of high and low noise Intensity is recorded due to the main busy road passing by the mall is connected to Keranitola traffic more (Figure 6).

\section{Heavy Traffic Zone Analysis}

Keranitala More (KM) and LIC More (LIC M) are the highly polluted area of heavy traffic zone. These more are the main junction of various roads connected to Midnapore town. Other districts and especially the Jindal factory of Salboni are also connected to Midnapore town through these two junctions. Hence a large number of vehicles are passing from the early morning and the noise level shows high intensity. Panchur Chak (PC) is a very busy junction as well as a market of daily necessities of a household. So the vehicles and the crowds are responsible for the high noise level. Ashok Nagar More (ANM) is also a busy road of this town and that is why highly polluted by traffic noise in all the seasons (Figure 6). 


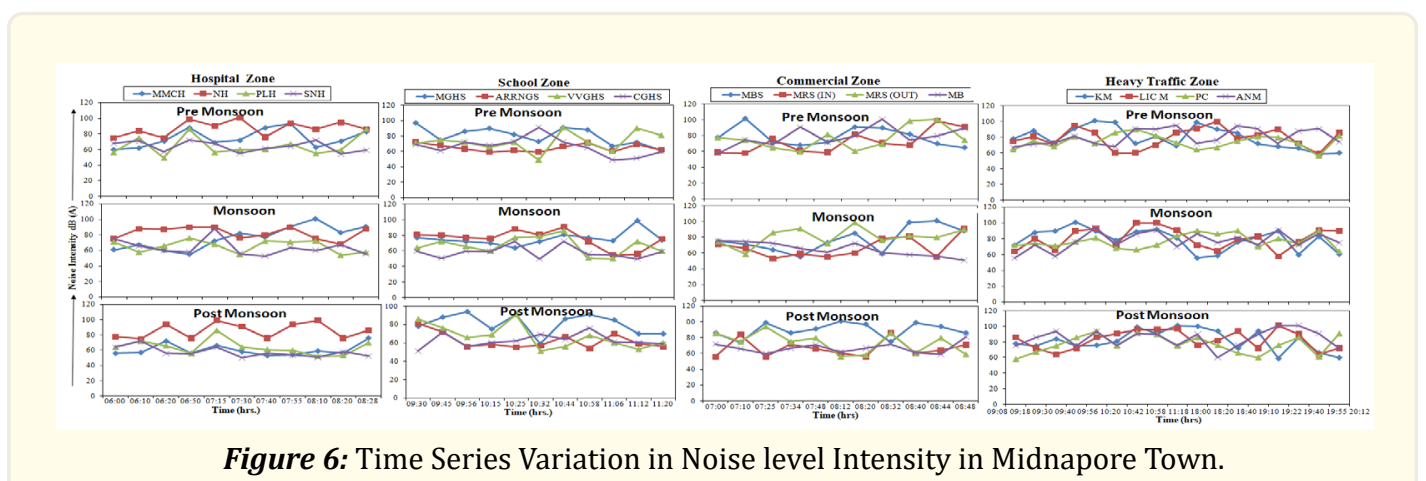

The Statistical analysis again reveals much higher noise intensity (Leq) than the recommended level in silent zones and commercial zones. Traffic Noise Index (TNI) is higher in all locations except the hospital zone. Noise Pollution Index (LNP) is also much higher in all locations of commercial and heavy traffic zones (Table 6).

\begin{tabular}{|c|c|c|c|c|c|c|c|c|c|c|c|}
\hline Location & Leq & $L 1$ & $L 5$ & $L 10$ & $L 50$ & $L 90$ & $L 95$ & $L 99$ & Lnp & $N C$ & TNI \\
\hline \multicolumn{12}{|c|}{ Hospital Zone,dB(A) } \\
\hline \multicolumn{12}{|c|}{ Premonsoon } \\
\hline MMCH & 74.5 & 92.5 & 90.2 & 88 & 73.3 & 62.4 & 62.7 & 63.8 & 100.1 & 25.6 & 134.8 \\
\hline$N H$ & 75.3 & 91.9 & 91.4 & 90.8 & 75.6 & 59 & 59 & 60.26 & 107.1 & 31.8 & 156.2 \\
\hline$P L H$ & 77.4 & 90.7 & 89.3 & 88 & 78.7 & 69.4 & 62.8 & 54.96 & 96.1 & 18.6 & 113.8 \\
\hline$S N H$ & 70.6 & 81.8 & 80.9 & 78.6 & 70.8 & 65.6 & 61.9 & 60 & 83.6 & 13 & 87.6 \\
\hline \multicolumn{12}{|c|}{ Monsoon } \\
\hline MMCH & 76.4 & 100 & 95.5 & 91 & 76.7 & 60.4 & 58.5 & 55.7 & 106.9 & 30.6 & 152.8 \\
\hline $\mathrm{NH}$ & 61.9 & 72.8 & 71.9 & 71 & 61.9 & 53 & 52.7 & 52.14 & 79.9 & 18 & 95 \\
\hline PLH & 69.6 & 89.1 & 85.0 & 80 & 70.3 & 58 & 56.8 & 54.6 & 91.6 & 22 & 116 \\
\hline$S N H$ & 77.3 & 90.7 & 89.4 & 87.4 & 77.3 & 68.6 & 66.7 & 66.14 & 96.1 & 18.8 & 13.8 \\
\hline \multicolumn{12}{|c|}{ Post Monsoon } \\
\hline MMCH & 60.3 & 75.6 & 73.8 & 70.8 & 58.5 & 54.8 & 53.7 & 53.14 & 76.3 & 16 & 88.8 \\
\hline $\mathrm{NH}$ & 64.9 & 84.9 & 84.5 & 82.4 & 64.9 & 53 & 50.7 & 50.1 & 94.3 & 29.4 & 140.6 \\
\hline PLH & 64 & 84.6 & 78.3 & 71.6 & 64 & 54.2 & 52.7 & 52.14 & 81.4 & 17.4 & 93.8 \\
\hline SNH & 57.5 & 71.2 & 67.6 & 64 & 56.7 & 51.4 & 50.7 & 50.1 & 70.1 & 12.6 & 71.8 \\
\hline \multicolumn{12}{|c|}{ Schools Zone, $d B(A)$} \\
\hline \multicolumn{12}{|c|}{ Premonsoon } \\
\hline MGHS & 79.5 & 96.3 & 93.4 & 90.7 & 79.5 & 69 & 65.2 & 61.8 & 101.2 & 21.7 & 125.8 \\
\hline ARRNGS & 66.3 & 80.0 & 75.6 & 72 & 66.3 & 60.4 & 59.7 & 59.1 & 77.8 & 11.6 & 76.8 \\
\hline VVGHS & 75.6 & 90.9 & 90.4 & 87.3 & 75.6 & 68.4 & 64.2 & 60.8 & 94.5 & 18.9 & 114 \\
\hline CGHS & 69.2 & 89.0 & 80.2 & 72.7 & 69 & 62.2 & 62.8 & 60.6 & 79.7 & 10.5 & 74.2 \\
\hline \multicolumn{12}{|c|}{ Monsoon } \\
\hline MGHS & 76.6 & 144.9 & 78.8 & 76.9 & 72.5 & 61.4 & 60.7 & 60.14 & 92.1 & 15.5 & 93.4 \\
\hline ARRNGS & 77.2 & 94.6 & 89.3 & 86.6 & 77.2 & 62.4 & 55.7 & 55.1 & 101.4 & 24.2 & 129.2 \\
\hline
\end{tabular}


Evaluation of Environmental Noise in Urban areas: A Noise Pollution Assessment Approach

\begin{tabular}{|c|c|c|c|c|c|c|c|c|c|c|c|}
\hline VVGHS & 78.9 & 114.1 & 91.8 & 85.6 & 77.9 & 64.8 & 64.2 & 60.8 & 99.7 & 20.8 & 118 \\
\hline CGHS & 67.5 & 110.1 & 76.0 & 72 & 63.7 & 55.4 & 53.5 & 50.7 & 84.1 & 16.6 & 91.8 \\
\hline \multicolumn{12}{|c|}{ Post Monsoon } \\
\hline MGHS & 79.5 & 96.34 & 93.4 & 90.8 & 80.75 & 68.5 & 64.9 & 61.78 & 22.3 & 22.3 & 127.7 \\
\hline ARRNGS & 66.3 & 80.01 & 75.6 & 72 & 66.1 & 60.3 & 59.65 & 59.13 & 11.7 & 11.7 & 77.1 \\
\hline VVGHS & 75.5 & 90.9 & 90.4 & 88.2 & 75.3 & 67.8 & 63.9 & 60.8 & 20.4 & 20.4 & 119.4 \\
\hline CGHS & 69.3 & 89.02 & 80.2 & 72.8 & 68.5 & 61.9 & 62.6 & 60.5 & 10.9 & 10.9 & 75.5 \\
\hline \multicolumn{12}{|c|}{ Commercial Zone, $\mathrm{dB}(A)$} \\
\hline \multicolumn{12}{|c|}{ Premonsoon } \\
\hline MBS & 79 & 123.4 & 96.5 & 90.9 & 79 & 68.6 & 67.1 & 65.4 & 101.3 & 22.3 & 127.8 \\
\hline MRS (IN) & 72.4 & 98.2 & 95 & 90.1 & 72.4 & 59 & 58.7 & 58.1 & 103.5 & 31.1 & 153.4 \\
\hline MRS (OUT) & 76.6 & 112.7 & 100 & 97.3 & 76.6 & 62.2 & 60.7 & 60.1 & 111.7 & 35.1 & 172.6 \\
\hline$M B$ & 79.1 & 100 & 96 & 90.9 & 79.1 & 69.9 & 65.7 & 69.42 & 100.1 & 21 & 123.9 \\
\hline \multicolumn{12}{|c|}{ Monsoon } \\
\hline$M B S$ & 77 & 100.8 & 100 & 97.9 & 77 & 60.5 & 57.8 & 55.6 & 114.4 & 37.4 & 180.1 \\
\hline MRS (IN) & 66.9 & 90.1 & 86 & 80.7 & 66.9 & 55 & 54.4 & 53.3 & 92.6 & 25.7 & 127.8 \\
\hline MRS (OUT) & 81 & 98.3 & 95 & 90.9 & 81 & 72.9 & 68.1 & 60.8 & 99 & 18 & 114.9 \\
\hline$M B$ & 64.5 & 74.9 & 74.5 & 73.8 & 64.5 & 56.6 & 54.5 & 51.7 & 81.7 & 17.2 & 95.4 \\
\hline \multicolumn{12}{|c|}{ Post Monsoon } \\
\hline$M B S$ & 90.2 & 100.8 & 99.9 & 99 & 90.6 & 79.4 & 74.7 & 76.54 & 109.8 & 19.6 & 127.8 \\
\hline MRS (IN) & 67.5 & 85.8 & 84.9 & 81.6 & 66.75 & 56 & 56 & 56 & 93.1 & 25.6 & 128.4 \\
\hline MRS (OUT) & 72.3 & 93.2 & 89.6 & 86 & 75 & 58.4 & 57.4 & 56.28 & 99.9 & 27.6 & 138.8 \\
\hline$M B$ & 66.6 & 80.1 & 76.0 & 72 & 66.8 & 60.4 & 59.7 & 59.1 & 78.2 & 11.6 & 76.8 \\
\hline \multicolumn{12}{|c|}{ Heavy Traffic Zone, $d B(A)$} \\
\hline \multicolumn{12}{|c|}{ Premonsoon } \\
\hline$K M$ & 79.8 & 105.3 & 102.5 & 100.2 & 79.8 & 62.4 & 59.7 & 59.14 & 117.6 & 37.8 & 183.6 \\
\hline LIC M & 79.1 & 99.3 & 96.5 & 90.6 & 79.1 & 64 & 66.7 & 60.82 & 105.7 & 26.6 & 140.4 \\
\hline$P C$ & 74.6 & 89.4 & 87.2 & 84.4 & 75 & 65.2 & 61.6 & 57.12 & 93.8 & 19.2 & 112 \\
\hline ANM & 80.3 & 94.9 & 94.3 & 92.8 & 88 & 72.8 & 72 & 72 & 100.3 & 20 & 122.8 \\
\hline \multicolumn{12}{|c|}{ Monsoon } \\
\hline$K M$ & 79.2 & 99.7 & 94.7 & 90 & 79.2 & 59.4 & 58.1 & 56.4 & 109.8 & 30.6 & 151.8 \\
\hline LIC M & 81.7 & 100 & 100 & 97.2 & 81.7 & 67.8 & 62.9 & 58.9 & 111.1 & 29.4 & 155.4 \\
\hline$P C$ & 77.5 & 90 & 90 & 90 & 77.5 & 67.6 & 68.2 & 64.8 & 99.8 & 22.4 & 127.2 \\
\hline ANM & 79 & 93.6 & 91.9 & 91 & 79 & 72 & 71.4 & 70.6 & 98 & 19 & 118 \\
\hline \multicolumn{12}{|c|}{ Post Monsoon } \\
\hline$K M$ & 82.5 & 100.8 & 100.3 & 99.6 & 86 & 62.4 & 59.7 & 59.14 & 119.7 & 37.2 & 181.2 \\
\hline LIC M & 83.5 & 100.4 & 98.2 & 96.6 & 90 & 72 & 69.6 & 65.12 & 108.1 & 24.6 & 140.4 \\
\hline$P C$ & 79.3 & 93.72 & 92.6 & 91.6 & 79.3 & 63 & 60.7 & 60.14 & 107.9 & 28.6 & 147.4 \\
\hline ANM & 85.1 & 101 & 101 & 98.2 & 90 & 73.6 & 68.4 & 61.7 & 109.7 & 24.6 & 142 \\
\hline
\end{tabular}


Evaluation of Environmental Noise in Urban areas: A Noise Pollution Assessment Approach

\begin{tabular}{|c|c|c|c|c|c|c|c|c|c|c|c|}
\hline \multicolumn{12}{|c|}{ Vidyasagar University, $d B(A)$} \\
\hline \multicolumn{12}{|c|}{ Premonsoon } \\
\hline VU IN & 62.4 & 79.7 & 69 & 67.8 & 62.4 & 54.6 & 53.4 & 52.3 & 75.6 & 13.2 & 77.4 \\
\hline VU OUT & 76.1 & 101.2 & 93 & 87.6 & 72 & 64.3 & 62.5 & 59.7 & 99.4 & 23.3 & 127.5 \\
\hline \multicolumn{12}{|c|}{ Monsoon } \\
\hline VU IN & 62.7 & 90. & 71.5 & 70.5 & 61 & 53 & 52.1 & 50.4 & 80.2 & 17.5 & 93 \\
\hline VU OUT & 76.5 & 110.6 & 92.5 & 90.7 & 76.5 & 59.3 & 57.2 & 53.8 & 107.8 & 31.4 & 154.9 \\
\hline \multicolumn{12}{|c|}{ Post Monsoon } \\
\hline VU IN & 59.3 & 73.2 & 65 & 64 & 59.3 & 52 & 51.7 & 51.1 & 71.3 & 12 & 70 \\
\hline VU OUT & 72.3 & 99.5 & 91 & 80.1 & 72 & 61.9 & 58.6 & 54.1 & 90.5 & 18.23 & 104.8 \\
\hline
\end{tabular}

Table 6: Different indices for estimating the Noise Pollution in Midnapore Town.

\section{Discussions}

The study reveals that most of the silent zones falls under Risky category, while a few also falls under Dangerous category, during the peak traffic hours of the day. The result discloses higher than recommended values in all locations of silent zones. Also, Noise Pollution Index (LNP) and traffic Noise Index (TNI) are very high mostly in commercial and heavy traffic zones. Noise climate (NC) values show not much relative variation in noise intensity with climate. This study can be used in predicting, planning, and managing further noise pollution in these areas. The location of any university, college, and school campus is a crucial factor in the noise pollution level inside each campus. The educational institutes should be situated in proper locations to prevent the noise pollution level inside the campus and should also be surrounded by proper greenery. To combat the noise pollution three major points should be maintained; Controlling/reducing sources of Noise; Controling/reducing the path of noise diffusion and controling/reducing the noise at arrival point.

The first step is easy to apply in our study locations; semi urban areas. The major noise pollution in these areas is attributed mainly due to the traffic and transportation noise. The following measures are suggested to combat noise pollution in these areas.

1. Preventing the use of old worn vehicles (with offensive engine sounds and annoying horns).

2. Using porous asphalt roads.

3. Afforestation and green paths near and surrounding heavy traffic zones and silent zones.

4. Contruction of sound insulation of the buildings to reduce the equivalent sound level (Such as including the absorbent materials, panels, and the use of suitable construction materials).

5. Implementing fines and ensuring strict measures for the vehicles with exceeded noise pollution.

6. Increasing the awareness of the people about the effects of noise pollution on their health.

Noise pollution is recognized as serious health and environmental problem. The development of urbanism, migrations, and the establishment of the transportation networks has reshaped this problem and has made it prominent in environmental problems. Proper and immediate measures must be implemented to manage the increasing noise pollution of these growing cities. As the continuous noise pollution causes harmful effect on human health it is recommended that we should be careful about this pollution. Especially particular focus should be given to control the noise pollution in silent zones and residential zones. It's time to think about the noise pollution menace and proper town and traffic control planning as well as the restriction on the use of microphones and speakers during religious or other activities and misuse of traffic horns. Afforestation near and around the silent and traffic zone can also help to solve the nuisance of noise pollution to some extent.

\section{Funding}

"This research received no external funding". 


\section{Conflicts of Interest}

"The authors declare no conflict of interest".

\section{References}

1. World Health Organization. "Burden of disease from environmental noise-Quantification of healthy life years lost in Europe". WHO Regional Office for Europe, Copenhagen, Denmark (2011).

2. Hogan CM and Latshaw GL. "The relationship between highway planning and urban noise". The proceedings of the ASCE. Urban Transportation. Chicago, Illinois. American Society of Civil Engineers: Urban Transportation Division (1973).

3. Ruggiero A. Department of Industrial Engineering, University of Salemo, Environ Pollut climate change 1 (2016): 1.

4. Clark C and Stansfeld SA. "The effect of transportation noise on health and cognitive development: A review of recent evidence". Int J comparePsychol 20 (2007): 145-148.

5. Evance GW., et al. "Chronic noise exposure and physiological response: A prospective study of children living under environmental stress". PsycholSci 9 (1998): 75-77.

6. Babisch W. "Noise and health". Environ Health Perspect 113.1 (2005): 14-15.

7. Jamrah A., et al. "Evaluation of Traffic Noise Pollution In Amman and Jordan". Environmental Monitoring and Assessment 120.13 (2006): 499-525.

8. Edmund YWS., et al. "Spatial Distribution of Traffic Induced Noise Exposures In a U.S City: An analytic tool For Accessing The Health Impact Of Urban Planning Decision". International Journal of Health Geographics 6.24 (2007): 1-16.

9. Babisch W. "Traffic Noise and Cardiovascular Disease: Epidemiological Review and Synthesis". 2.8 (2000): 9-32.

10. Lundberg U. “Coping with Stress: Neuroendocrine Reactions and Implications for Health”. Noise Health 1.4 (1999): 67-74.

11. Zannin PHT., et al. "Evaluation of the noise pollution in urban parks of Curitiba". Environmental Monitoring and Assessment 118 (2005): 423-433.

12. Taoa Li B., et al. "GIS based road traffic noise prediction model”. Applied Acoustics 63 (2002): 679-691.

13. Alam JB., et al. "Study on traffic noise level of sylhet by multiple regression analysis associated with health hazards". Iran, J.Environ. Health. Sci.Eng 3.2 (2006): 71-78.

14. Murthy VK and Khanal SN. "Assessment of traffic noise pollution in Banepa, a semi urban town of Nepal". Kathmandu University, Journal of Science, engineering and technology 1 (2007): 1-9.

15. Bajj MH., et al. "Modelling noise at elevated highways in urban areas: a practical application". Journal of Urban Planning and Development 127.4 (2001): 169-180.

16. Fyhri A and Klae R. "Road traffic noise sensitivity, annoyance and self-reported health- A structural equation model exercise". Environment International 35.1 (2009): 91-97.

17. Shetye RP., et al. “The noise festivals: canwe not change?". Scavanger (1981): 3-8.

18. Ravichandran C., et al. "Noise pollution assessment in Pudukkottai, Tamil Nadu”. Polln. Res 19.3 (2000): $431-434$.

19. Pandya M and Shrivastava RK. "Analysis of noise levels and its health effects in commercial areas of Jabalpur city: Part I-Analysis of health effects". Indian J. Environ. Sci 4.1 (1999): 197-200.

20. Santra SC. Status of noise pollution studies in Kolkata and current state of legal measures for abatement, Environment Issues and Challenges, Academic Staff College, The University of Burdwan, Burdwan 2 (2000).

21. Pal D and Bhattacharya D. "Effect of road traffic noise pollution on human work efficiency in government offices, Private Organizations, and Commercial Business Centres in Agartala City Using Fuzzy Expert System: A Case Study”. Advances in Fuzzy Systems (2012): 1-9.

22. Patel R., et al. "A study of noise pollution at the campus of Madan Mohan Malaviya University of Technology Gorakhpur, Uttar Pradesh (India)". International Research Journal of Engineering and Technology (IRJET) 4.2 (2017): 1258-1263. 
23. Roy M., et al. "An Analysis of Noise Pollution in Bankura City, W.B, India". International Journal of Pollution and Noise Control 5.2 (2019): 26-40.

Volume 2 Issue 2 February 2022

(C) All rights are reserved by Misha Roy., et al. 